Referencia para citar este artículo: Cárdenas-Forero, Ó. L., Aguilera, Y., \& Silva, D. P. (2018). Historia del saber escolar estético en el preescolar. Revista Latinoamericana de Ciencias Sociales, Niñez y Juventud, $16(2), 695-707$. doi:https://doi.org/10.11600/1692715x.16204

\title{
Historia del saber escolar estético en el preescolar*
}

\author{
ÓSCAR LEONARDo CARDENAS-FORERo ${ }^{* *}$ \\ Profesor Universidad del Tolima, Colombia. \\ YENNY AGUILERA *** \\ Estudiante Universidad del Tolima, Colombia. \\ Diana PaUlina SILVA \\ Estudiante de la Universidad del Tolima, Colombia.
}

\section{Artículo recibido en octubre 2 de 2017; artículo aceptado en enero 24 de 2018 (Eds.)}

- Resumen (descriptivo): el presente artículo de reflexión, enmarcado en una perspectiva cualitativa, es un trabajo fundamentado en las exploraciones realizadas en el Semillero de Investigación "Historia de los Saberes Escolares en el Preescolar», alrededor del estudio de las condiciones de existencia que funcionaron acopladas durante la década de los 80 para permitir la introducción de los saberes escolares - en particular del saber escolar estético-, en el preescolar de la escuela pública bogotana, a modo de un contenido de enseñanza que recurre a las herramientas que proporciona el enfoque arqueológico-genealógico foucaultiano para describir su origen, su función y su funcionamiento dentro del andamiaje escolar, y que sirvió de complemento a las estrategias de regulación, preescolarización y formación de los niños y niñas durante esa época.

Palabras clave: Saberes escolares, educación estética, preescolar, escuela pública (Tesauro de Ciencias Sociales de la Unesco).

\section{History of aesthetic educational knowledge in preschools}

- Abstract (descriptive): This short article that uses a qualitative perspective is based on the explorations carried out by "History of Educational Knowledge in Preschool" Research Group. The purpose of this article is to highlight the conditions that existed during the decade of the 1980s

Este artículo de investigación científica y tecnológica hace parte del proyecto «La historia de los Saberes Escolares en el Preescolar de la Escuela Pública», financiado por la Universidad del Tolima, en el marco de las exploraciones realizadas por el Semillero de Investigación «Historia de los Saberes Escolares en el Preescolar» e inscrito con el código: 190414, realizado entre el año 2014 y el 2016 y que antecede a la producción final de un documento sobre «La Historia de los Saberes en el Preescolar de la Escuela Pública Bogotana (1980-1990)». Áreas: Historia y Educación. Subáreas de Conocimiento: Educación.

** Profesor de la Universidad del Tolima, Colombia. Licenciado en Ciencias Sociales de la Universidad Distrital Francisco José de Caldas. Especialista en Gerencia de Instituciones Educativas de la Universidad del Tolima. Máster en Desarrollo Educativo y Social Convenio CindeUPN. Ponente en el IV Coloquio Latinoamericano de Biopolítica. Docente del Colegio Entre Nubes S. O. IED (Colombia). Coordinador del Semillero de Investigación «Historia de los Saberes Escolares en el Preescolar» y del Grupo de Investigación «Historia de las Disciplinas Escolares» avalados por la Universidad del Tolima. Orcid: 0000-0003-4894-7888. Índice H5: 3. Correo electrónico: osle1972@gmail.com

*** Estudiante de la Universidad del Tolima, integrante del Semillero de Investigación «Historia de los Saberes Escolares en el Preescolar» adscrito a la Universidad del Tolima. Orcid: 0000-0002-1288-3264. Índice H5:1 Correo electrónico: yeriag@yahoo.es

**** Estudiante de la Universidad del Tolima, integrante del Semillero de Investigación «Historia de los Saberes Escolares en el Preescolar» adscrito a la Universidad del Tolima. Orcid: 0000-0003-4739-5989. Índice H5:1 Correo electrónico: dpaulinasilva@ut.edu.co 
that led to the development of school knowledge, particularly aesthetic knowledge, within public preschool education in Bogota, in terms of teaching practices. The article uses tools provided by Foucault's archaeological-genealogical approach to describe the origin, function and functioning of aesthetic school knowledge in schools, which served as a complement to the strategies of regulation, preschool and the education of children during this period.

Key words: School knowledge, aesthetic education, preschool, public school (Unesco Social Sciences Thesaurus).

\section{História do conhecimento estético da escola pública na educação pré-escolar}

- Resumo (descritivo): este artigo curto, enquadrando em uma perspectiva qualitativa, é um trabalho baseado nas explorações realizadas no grupo de pesquisa "História dos saberes escolares na pré-escola". A intenção deste artigo é mostrar as condições de existência que funcionaram acopladas durante a década da 80 para permitir a introdução dos conhecimentos escolares, particularmente o conhecimento estético da educação pré-escolar na escola pública de Bogotá, como um conteúdo de ensino, que recorre às ferramentas fornecidas pela abordagem arqueológico-genealógica de Foucault para descrever sua origem, função e funcionamento dentro da escola e que serviu de complemento às estratégias de regulação, escolaridade e formação da crianças durante esse período.

Palavras-chave: Conhecimento escolar educação, estética, pré-escolar, escola pública (Tesauro de Ciências Sociais da Unesco).

-1. Preludio. -2. Los saberes escolares. -3. La introducción de la preescolarización en la escuela primaria de los años 80. -4. El movimiento pedagógico nacional. -5. De la renovación curricular. -6. La enseñanza en el preescolar. -7. Los saberes en la forma de materias escolares. La educación estética: la creatividad sensibiliza. -8. El dibujo: hacia los primeros trazos infantiles. -9. La literatura Infantil. -10. Las dramatizaciones. -11. La educación musical. -12. Reflexiones finales. -Lista de referencias.

\section{Preludio}

Recientemente los estudios e investigaciones alrededor de los saberes escolares han estado constituyéndose en nuevos territorios de búsquedas que permiten reconocer las diversas maneras como la escuela en el tiempo ha diseñado, producido, seleccionado e implementado una serie de contenidos para adelantar, complementar y establecer formas de ser de la enseñanza y de la escolarización de los niños y niñas. De este modo, la escuela no solo se ha encargado de regular y educar a los sujetos escolares sino, además, de elaborar las estrategias, los mecanismos y las materializaciones, en la forma de saberes, asignaturas, materias escolares y contenidos de enseñanza, para instruirlos y educarlos en el conocimiento y la ciencia, los cuales han emergido no simplemente como «entidades monolíticas, sino [como] amalgamas cambiantes de subgrupos y tradiciones» (Goodson, 1991, p. 60), como invenciones temporales y no como refracciones de un determinado conocimiento o saber científico, que se articulan a la racionalidad de cada época, alejándose de aquella idea que las considera como una instancia de reproducción de lo social, de lo económico o, por supuesto, del saber construido en escenarios académicos o universitarios.

A pesar de constituirse en un escenario naciente y de referencia para dar cuenta de la escuela — de una condición específica de ser de la escuela, es decir, asociada al conocimiento-, y de los modos como se ha asumido y constituido la enseñanza, en el caso particular del preescolar se mantiene aún como un campo inexplorado y de limitado lugar de indagación por parte de la investigación histórica, pedagógica y educativa, lo cual se configura en una posibilidad para adentrarse con nuevas rutas, enfoques, herramientas de trabajo y métodos frente a la historia del preescolar, y con ello, irrumpir en el territorio de problematizar los asuntos referentes al currículo y a la enseñanza preescolar, en 
particular en términos de los contenidos de enseñanza que se introducen en la formación infantil.

Es por ello que al incursionar en este terreno buscamos describir la génesis, la función y la forma de funcionamiento que adoptaron los saberes escolares en el preescolar público ofrecido por el Estado y adscrito a la escuela primaria — en específico el saber estético-, saberes que para entonces, en la década de los ochenta, se concretaron como materias de enseñanza asociadas a las áreas de conocimiento.

Así, el trabajo se convierte en una apuesta por contribuir en la constitución de un campo propio de este saber y en la producción de estudios alrededor de la historia de los saberes escolares en el preescolar, ubicándonos en concreto en el preescolar que floreció y se articuló a la educación primaria de la escuela pública bogotana en la década de los años 80, momento en el que, precisamente, se integraba a las dinámicas y a la estructura del sistema educativo formal del país.

Para lograr esto, metodológicamente el trabajo atraviesa unos momentos que inician con la revisión documental; enseguida definimos las fuentes de información, hacemos la lectura, tematización y fichaje de la información recolectada y seleccionada, para desembocar en el establecimiento de agrupaciones y espacios que permitirán dar cuenta del acontecimiento objeto de estudio.

En este proceso, quienes investigamos asumimos el rol del arqueólogo o arqueóloga que rastrea en el archivo los indicios, vestigios y las pesquisas que se han instaurado como certezas en una época, para lo cual exploramos las fuentes primarias en las que se encuentran los enunciados, para después investirnos con el ropaje del sujeto geneálogo que explora en el tiempo los juegos de poder, las acciones que interactúan con otras acciones y las tensiones que se suscitan alrededor del acontecimiento abordado.

\section{Los saberes escolares}

Los saberes escolares, sean producciones de la escuela o elaboraciones hechas en la escuela misma (véase al respecto Marín, 2015), son acontecimientos articulados al andamiaje de cada época, a las prácticas que interactúan en determinados momentos; por tanto, independientemente del lugar de procedencia, de los propósitos que los encausen, de los contenidos escogidos, de quienes los produzcan, estos se encuentran acoplados a la racionalidad de cada momento histórico y no siempre están articulados a las áreas de conocimiento o a las producciones científicas o universitarias elaboradas.

Por consiguiente, los saberes escolares se consideran creaciones que obedecen a estratos históricos singulares, a una manera particular de ser de la escuela que, por tanto, no la precedieron, sino que aparecen posteriores a su emergencia, como asuntos asociados a una intención concreta de hacer de la escuela, es decir, como un lugar para el conocimiento. Esta condición que los desnaturaliza del acontecer escolar implica reconocer que, así como muchos saberes se generan en cada época, otros tienden a transformarse, otros a subsistir y trascender, pero otros, por el contrario, tienden a desvanecerse en el tiempo, lo cual significa comprender que no siempre han existido en la escuela y que ni siquiera han adoptado un modo similar, sino que en cada momento histórico se han constituido de formas diversas obedeciendo a la racionalidades de cada época.

Así entonces, los saberes escolares trascienden la idea de considerarse como adaptaciones del conocimiento elaborado por las comunidades académicas, como reflejos de la producción erudita, transposiciones del saber científico o imágenes adaptadas de la ciencia, sino que se institucionalizan como invenciones propias de la escuela y de su tiempo, con una historia propia, acoplamientos de cada época que dan cuenta del acontecer escolar, de sus tensiones, de la cultura, de los ideales sociales y escolares, de lo que se legitima como contenido para enseñar y aprender, en síntesis, de lo que los niños y niñas deben apropiar de la cultura para comprenderla y desenvolverse en ella.

Respecto a esto, Chervel (1991) señala que los saberes escolares no siempre han tenido la misma forma, carácter ni concepción o han estado relacionados con esa representación de aquello que se enseñanza o con lo que es susceptible de ser enseñado, es decir, con los contenidos o materias 
académicas sino que más bien, en un comienzo tuvieron una connotación particular que en el tiempo se ha transfigurado para constituirlos en invenciones históricas acordes a modos singulares de ser de la educación y la escuela, de la sociedad, cuya selección e introducción no obedece a la voluntad de algún gremio, grupo, sujeto, normatividad, política educativa u ordenanza del Estado, sino a la confluencia de múltiples prácticas sujetas a reglas de funcionamiento de cada período histórico, que fortalecieron la idea de hacer de la escuela un escenario para la adquisición y producción del conocimiento.

En este sentido, Chervel (1991) muestra, además, cómo este concepto de disciplina escolar apareció por primera vez en la educación primaria y estuvo relacionado con aquella parte de la educación que se empleaba para reprimir las «conductas susceptibles de alterar el orden establecido» (p. 60), emparejándose con el término disciplinar y con la idea de «gimnasia intelectual», adquiriendo la forma de «la instrucción que el alumno recibe del maestro» (p. 61).

Sin embargo, es hasta el siglo XX cuando se vinculó el saber escolar con aquello que se debe enseñar, asumiendo una nueva forma en la que se le concibe como un «conjunto específico de conocimientos que tiene sus características propias en el ámbito de la enseñanza, la formación, los mecanismos, los métodos y las materias» (p. 60), es decir, como esa conjunción de contenidos propios de la cultura que los niños y niñas deben apropiarse para movilizarse en la vida social; así, los saberes empiezan a instituirse como esas «formas de transmisión cultural que se dirigen a los alumnos» ( $\mathrm{p}$. 70), las cuales se deben asumir como propias a través de la enseñanza ofrecida por los maestros y maestras.

De este modo, el concepto de saber escolar, acogiendo los argumentos de Álvarez (2008), terminó asociado simplemente a un listado de materias que se enseñan en la escuela, olvidando el propósito de formar la inteligencia, la razón y el espíritu, trascendiendo la razón de los contenidos mismos. Por consiguiente, «hoy en día el término disciplina todavía alude al espacio delimitado de conceptos que diferencian un campo de saber de otro, enmarcándolo exclusivamente en el ámbito de los contenidos» (p. 4), manera singular que se ha venido diluyendo de las prácticas de enseñanza en el preescolar público.

\section{La introducción de la preescolarización en la escuela primaria de los años 80}

A comienzos de la década de los 80 se introducía en la escuela primaria pública de Bogotá, como efecto de la «expansión vertical de la escuela» (Martínez-Boom, 2004, p. 138), la preescolarización en la forma de una pre-escuela y como una estrategia fundamental de estimulación temprana para reducir y enfrentar la repetición, el fracaso, la deserción escolar primaria. Con ello se pretendió impulsar e instaurar unas condiciones singulares para preparar y aprestar a los niños y niñas para enfrentar los desafíos de la educación primaria.

Para ese entonces, en la mayoría de concentraciones escolares del Distrito Especial, existía solamente un grupo de niños y niñas de preescolar por escuela, que por lo general lo ubicaban «en el aula menos apropiada para desarrollar satisfactoriamente la labor educativa, pues son aulas acondicionadas y no cumplen los requisitos mínimos de comodidad, decoración, ubicación, ni adecuación» (Martínez, 1983, p. 48).

En estas condiciones el preescolar se fue gestando dentro de la escuela como el nivel inicial del sistema educativo formal y público orientado a atender a una población infantil entre los $5 \mathrm{y}$ los 6 años de edad, que por efecto de múltiples prácticas que convergieron — como la necesidad de proteger a la infancia, de establecer una sociedad igualitaria y equitativa, la incursión de la mujer al mercado laboral, entre otras-, se pretendió complementariamente «asegurar su acoplamiento en el nivel primario, secundario, y muy posiblemente en el nivel profesional» (p. 48).

Como consecuencia, se fueron proponiendo acciones de intervención y de mejoramiento de las condiciones de la educación preescolar, entre las que se destacan la dotación de la infraestructura requerida en las instituciones educativas públicas, el equipamiento de los recursos didácticos, 
recreativos y deportivos necesarios, así como el mobiliario obligatorio para el buen desarrollo de las actividades preescolares, el trabajo eficiente con los niños y niñas y, por supuesto, la inclusión de ciertos contenidos de enseñanza para adelantar los procesos de formación de los niños y niñas, con lo que se fue estableciendo y resaltando el valor del nivel preescolar como base del sistema educativo colombiano.

Con esto se contempló la necesidad de introducir una función complementaria y distinta para el preescolar y para lo que allí se enseña; es decir, trascender su papel como instancia para el aprestamiento escolar de los niños y niñas y considerar la posibilidad de su papel potencial y de estimulación prematura en la promoción de su desarrollo comunal e integral. De este modo, la enseñanza y aquello que se debía enseñar se empezó a relacionar con el desarrollo intelectual, con el aprendizaje de la lectoescritura y las matemáticas, con algunos elementos básicos para afrontar exitosamente la educación primaria y con los campos del conocimiento. Así, la concepción de preescolar como instancia previa a la educación primaria favoreció la constitución de un currículo disciplinar en el que se ubicaran aquellas materias escolares requeridas para evitar el fracaso escolar, la deserción, y resultados no esperados en la primaria.

\section{El Movimiento Pedagógico Nacional}

A comienzos de los años 80, como efecto de la renovación curricular impulsada por el gobierno a través del Ministerio de Educación Nacional, emergió, articulado a una multiplicidad de condiciones, el Movimiento Pedagógico Nacional, una alternativa pedagógica, ética y política de los maestros y maestras que tenían interés en una transformación efectiva y contextual del sistema educativo del país, más acorde con las necesidades y dinámicas de cada escuela, que contribuyó a la constitución de un maestro distinto, crítico, en diálogo constante con los académicos, productor de saber pedagógico, dinamizador de la construcción de currículos acordes con los requerimientos de los niños, niñas y jóvenes; un sujeto político preocupado por el acontecer de la escuela y la pedagogía.

En estas condiciones, surgía articulado a la escuela primaria pública bogotana el preescolar, y con este acontecimiento irrumpió también la maestra de preescolar, quien se vio abocada no solo a enfrentar los retos que el Movimiento Pedagógico le proponía, sino a reflexionar sobre lo que se debía enseñar en este nivel educativo.

En ese sentido, Cárdenas-Forero (2015a) menciona que las maestras de preescolar estuvieron «ausentes de la realidad educativa del momento, de los discursos formulados, de las acciones efectuadas, de las publicaciones, eventos y congresos realizados, haciendo difusa y casi imperceptible su actuación e intervención en las dinámicas del movimiento mismo» (p. 657), lo que se debió a cuestiones relacionadas con la introducción de discursos psicológicos que exaltaban el valor de los niños y niñas en el proceso educativo en los que se supeditaba la intervención del sujeto docente.

Cabe señalar que la insinuación de la preescolarización en la escuela pública requirió de la atención de las maestras en términos de organizar unos contenidos, prácticas, tiempos y lugares para la enseñanza ante la poca claridad respecto a estos asuntos, lo cual no significó que el movimiento las mantuviera al margen.

Es por esto que hacia 1987, en el Congreso Pedagógico Nacional auspiciado por la Federación Colombiana de Educadores (Fecode), se posibilitó un encuentro de experiencias de los maestros y maestras a través de ponencias que permitieron develar el potencial de sus producciones pedagógicas, investigativas y académicas, se describió que la práctica pedagógica en el preescolar presentaba una marcada tendencia a la prematura adquisición de las habilidades de lectura, escritura y matemáticas, desconociendo las verdaderas necesidades y posibilidades de los niños y niñas en esta edad.

Se dijo - como complemento de esto - que en muchas instituciones de formación de docentes para este nivel existía poca claridad respecto a los requisitos, contenidos y objetivos de los programas; sin embargo, se hacían esfuerzos por parte del Ministerio de Educación Nacional para enfrentar estas dificultades, reflejado ello en el diseño de una propuesta de currículo de preescolar que emergió a 
mediados de los 80 y que contenía las orientaciones necesarias a considerar para afrontar su quehacer pedagógico en el aula.

\section{De la renovación curricular}

Hacia 1975 se instauró con fortaleza la Tecnología Educativa en el sistema educativo nacional, como una tendencia para orientar sus políticas, acciones y estrategias, que se apoyó en la introducción del Programa de Mejoramiento Cualitativo de la Educación, que funcionó «para (...) la concreción de una nueva manera de concebir la organización y funcionamiento de todo aparato educativo: la creación del sistema educativo; para la enseñanza y la escuela (...) la implantación de la tecnología instruccional» (Martínez, Noguera, \& Castro, 1994, p. 147). Gracias a este proceso las ideas «de la calidad y del mejoramiento cualitativo de la educación» (Vasco, 2011, p. 24) tomaron vigencia y se introdujeron en las prácticas escolares de la época, transformando «precisamente, de los modos como los maestros enseñaban, planeaban y seleccionaban los saberes y actividades para llevar a cabo su labor pedagógica» (Cárdenas-Forero, 2015b, p. 95).

Este proceso de cambio educativo que impulsó la Tecnología Instruccional o Tecnología Educativa, auspiciado por el Ministerio de Educación Nacional, significó la adopción por parte de los maestros y maestras de unos contenidos de enseñanza prefijados, en «la forma de un paquete elaborado por instancias técnicas y administrativas alejadas de la institución escolar, y dispuesto para su aplicación y utilización operativa por parte del maestro» (Martínez et a, 1994, p. 120) y que significó mostrar los saberes escolares como una serie de contenidos de enseñanza formulados por instancias externas a la escuela, la pedagogía como un discurso instrumentalizado y el maestro o maestra como un individuo ejecutor de planes de estudio preestablecidos.

Ahora bien, para la educación preescolar ofrecida por el Estado, la programación de la enseñanza implicó

(...) la necesidad de comprender este proceso como la organización del tiempo y del espacio donde se realizaban las acciones con el grupo de niños, el manejo de los espacios del vecindario que podían ser utilizados en los procesos educativos, las estrategias a implementar (juego libre), los modos de estructurar los contenidos de enseñanza (unidades de trabajo) y el empleo de recursos necesarios (materiales didácticos, juguetes, etc.) para la ejecución de las acciones escolares. (Cárdenas-Forero, 2015b, p. 95)

Dicha Renovación Curricular se presentó como un intento para el mejoramiento educativo en los niveles de Pre-escolar, Básica (Primaria y Secundaria) y Media Vocacional, que comprendió la formulación de unos fundamentos legales, filosóficos, epistemológicos, sociológicos, psicológicos y pedagógicos, y que estuvo respaldada por la promulgación de una serie de disposiciones legales que tendieron a transfigurar tanto las maneras de enseñar en la escuela como al maestro y su labor pedagógica y educativa; y por supuesto, el preescolar de la escuela pública no fue ajeno a esta coyuntura, ya que muchas maestras que asumieron el reto de la preescolarización en el marco de la escuela pública, fueron inicialmente en su mayoría maestras de primaria, responsables en muchos casos de asumir esta floreciente obligación.

Según Cárdenas-Forero (2016), estas maestras seleccionadas eran profesionales «que tuvieran un perfil para tratar niños pequeños, o maestros que hubiesen tenido el título de normalistas» (p. 46) cuya labor se orientó a programar la enseñanza, las prácticas curriculares y la selección de los contenidos incluidos para complementar los procesos de escolarización.

\section{La enseñanza en el preescolar}

Cuando incursiona el preescolar en la escuela pública de los años 80, la enseñanza se ve enfrentada a muchas dificultades relacionadas con la escasa claridad respecto a lo que se debía 
enseñar a los niños y niñas durante su permanencia en este grado de escolaridad, lo que en cierta medida se debió a la ausencia de unas orientaciones y políticas curriculares precisas para este nivel educativo. Precisamente, esta poca claridad y la ausencia de unas directrices específicas respecto a los contenidos de enseñanza a involucrar en las clases, y por supuesto, respecto a su selección, circulación y producción, obligaron en cierta medida a que las maestras de entonces recurrieran a sus experiencias pedagógicas, a sus criterios personales de enseñanza, a los conceptos apropiados en el tiempo de su formación universitaria o a sus concepciones particulares sobre la educación y la escuela para adelantar las acciones de enseñanza preescolar.

Pero además, se hizo prioritario incluir en sus requerimientos y exigencias la preocupación por la pregunta sobre el qué enseñar a los niños y niñas en el preescolar, hasta el momento un asunto difuso, poco recurrente y visible en sus debates, pues a pesar de que se consideraba el preescolar como un estado preliminar de aprestamiento para enfrentar la escuela primaria, justamente no había claridad respecto a las orientaciones a seguir para afrontar la enseñanza y los saberes a introducir, orientados a iniciar los procesos de escolarización y formación infantil. No obstante, dicha situación se iba a comenzar a modificar más adelante con la introducción por parte del Ministerio de Educación Nacional de un currículo formulado para el preescolar.

Al momento de ingresar y nombrarse maestras para este nivel educativo, y ante las pocas maestras existentes para adoptar este compromiso, a quienes se lo adjudicaron fue precisamente a aquellas maestras de primaria de quienes se consideró que tenían las capacidades y los perfiles para enfrentar la emergencia del preescolar en la escuela pública, y quienes ante la ausencia de esas políticas curriculares, optaron por replicar las prácticas de enseñanza que realizaban en la primaria. Estas prácticas de enseñanza estuvieron enmarcadas por tendencias primarizantes, reproduccionistas y tradicionales, propias del modelo educativo instaurado; pero además, por la promoción de aprendizajes mecánicos y memorísticos y el conocimiento de contenidos de enseñanza a modo de materias escolares para aprobar y garantizar un buen rendimiento y evitar la deserción y el fracaso escolar.

Respecto a esto, las maestras de la época manifestaron que «(...) antes el currículo se establecía en una formación disciplinaria, rígida y una adaptación fuerte en valores, lo que en esa época exigía esa sociedad» (León, 26 de junio de 2015).

Es importante resaltar que en nivel preescolar se enseñaban «todas las materias, pero lo básico y lo más importante eran las matemáticas y español. Aritmética, lectura (...)» (Boada, 10 de octubre de 2015); del mismo modo, «los aprendizajes venían estipulados en temas para cada área. El maestro debía apegarse a la programación de éstos, básicamente enseñar a leer y a escribir, operaciones matemáticas y otros aprendizajes de convivencia y formación religiosa» (Morales, 12 de febrero de 2015), todos ellos planteados para favorecer, entre otras cosas, «(...) la motricidad gruesa y fina para que el niño llegue a la primaria con buenas bases» (Castellanos, 5 de marzo de 2014).

Ahora bien, según el decreto 1419 (República de Colombia, Ministerio de Educación NacionalMEN-,1978), los componentes de los programas curriculares para cada área o asignatura en los niveles preescolar, básica — primaria y secundaria_-, media vocacional e intermedia debían contener entre otros aspectos, unos contenidos básicos que apoyarían los procesos de enseñanza en la escuela de forma integrada iniciando la orientación vocacional, lo que significó la necesidad de proponer unas materias, temas o asignaturas para cada uno de estos niveles de educación formal para alcanzar esas metas educativas.

Por su parte, con la aparición del decreto 1002 (República de Colombia, Ministerio de Educación Nacional-MEN-, 1984), se buscó afianzar aún más la necesidad de otorgarle a la educación preescolar el carácter de instancia previa y definitiva para la educación posterior de los niños y niñas, y para esto se consideró muy importante establecer un plan de estudios orientado no solo al desarrollo integral y armónico sino complementariamente al aprestamiento adecuado para su ingreso a la educación básica. No obstante, en esta disposición se aclaró que para este nivel educativo no se debían determinar áreas ni grados específicos, sino que se debía aprovechar, crear y convertir en ambiente educativo la realidad social en que vivía el niño o niña, utilizando los recursos y materiales propios de la 
comunidad, adecuando los contenidos de enseñanza y duración de las actividades a sus intereses y de acuerdo con las características de su desarrollo.

Con todo ello, se exaltó el valor del juego como actividad básica para el desarrollo de los aprendizajes de los niños y niñas, la necesidad de propiciar entre ellos el trabajo en grupo para iniciar procesos de socialización, fomentar el espíritu de cooperación y amistad y, por supuesto, el desarrollo de su autonomía, cada uno de estos aspectos integrados a la intención del preescolar de servir como aprestamiento para la educación básica primaria; sin embargo, como se ve, en estas disposiciones era poca la claridad que se expresaba alrededor de los contenidos de enseñanza que se debían introducir en el preescolar.

Como una propuesta complementaria, hacia 1986 el Ministerio de Educación Nacional (MEN) designó a la División de Diseño y Programación Curricular de Educación Formal, de la que hizo parte el grupo de Pre-escolar, para establecer una serie de políticas y lineamientos que contribuyeran a la regulación de la actividad curricular de todos los niveles del sistema educativo del país, que se materializó en la elaboración de unas orientaciones curriculares orientadas a la introducción de un Currículo para el Preescolar dirigido a niños y niñas de 4 a 6 años de edad de las instituciones de educación formal, lo que favoreció la incorporación de unos contenidos de enseñanza articulados a unas temáticas de las áreas del conocimiento, que incluyó dos documentos publicados en diferentes momentos, en los que se orientó a los maestros y maestras de preescolar sobre su trabajo en el aula mas no como un programa para la educación de los niños y niñas.

Desde luego, estos contenidos de formación se concibieron como lineamientos que le proporcionaban información solamente al maestro o maestra, y en consecuencia debían simplemente ser aprovechados para facilitar y permitir al niño o niña algunas experiencias integradas, que lo condujeran a una comprensión adecuada de la realidad, de acuerdo con su proceso de desarrollo; por tanto, se señaló que el espíritu del currículo estaba enfocado a «ampliar el horizonte del conocimiento del niño, para estimular su deseo de aprender y de crecer integralmente» (p. 7).

Para ese momento se reconoció adicionalmente que el desarrollo infantil era un proceso que se podía articular a los contenidos de enseñanza de las áreas de conocimiento. Esto hizo que para el preescolar se formulara una serie de temas relacionados con áreas de formación, como Educación Estética, Educación Física, Educación Sexual, Ciencias Sociales, Educación Religiosa, PrelectoEscritura y Prematemática, con las que además se buscó garantizar una adecuada preparación de los niños y niñas para enfrentar las actividades de la educación primaria, pues se consideraba «que en el niño no se desarrollan aspectos independientes del contenido» (República de Colombia, Ministerio de Educación Nacional-MEN, 1987, p. 17) y «que en toda actividad siempre hay un contenido explícito o implícito» (p. 77), con lo que se justificó la introducción de estos contenidos de enseñanza en el preescolar.

Como se ve, la enseñanza estaba asociada a una serie de contenidos de enseñanza propios de las áreas de formación y las asignaturas como lecto-escritura, salud, matemáticas, ciencias sociales, ética, religión, educación estética, que servían de referentes para adelantar los procesos de formación y aprestamiento para la educación primaria. Todo ello se enseñaba «para que cuando entraran los niños a primero tuvieran las condiciones requeridas y así no tuvieran problemas para aprender a leer, escribir, sumar y restar» (Castellanos, 5 de marzo de 2014); sin embargo, por lo menos en el preescolar público, dichos contenidos se han ido diluyendo por efecto de unas prácticas emergentes y de unas maneras singulares de ser y concebir este nivel educativo.

\section{Los saberes en la forma de materias escolares. La educación estética: la creatividad sensibiliza}

Cuando floreció el preescolar en la escuela primaria pública en la década de los 80 , una de las situaciones a las que se enfrentó la maestra de preescolar fue a la pregunta por la enseñanza, por los contenidos que se debían introducir para adelantar los procesos de formación infantil y que orientarían 
sus prácticas pedagógicas, pues no solamente era un acontecimiento en la escuela sino que además había poca claridad sobre las directrices para asumir ese reto, las disposiciones eran escasamente conocidas y la pregunta por la enseñanza era un asunto difuso entonces.

Una de las perspectivas que se introdujo era que el desarrollo infantil debía articularse a las áreas de formación. Y una de las áreas que se incorporó en el preescolar de la escuela pública fue precisamente el saber escolar estético, el cual se hizo específicamente a través de cuatro temáticas fundamentales: el Dibujo que se relacionó con los primeros trazos realizados por los niños y niñas, la Literatura Infantil que incluyó como textos de trabajo base los cuentos y la poesía, la Dramatización que integró el Teatro y las representaciones con Títeres, y la iniciación a la Educación Musical, cuya introducción se justificó como un complemento a las demás áreas de conocimiento, ya que «si un niño aprende algo y al mismo tiempo lo asocia con una canción, con un cuento, con una representación, habrá logrado una educación integral» (República de Colombia, Ministerio de Educación Nacional-, 1987, p. 86).

\section{El dibujo: hacia los primeros trazos del niño}

Al momento de incluir el dibujo como uno de los contenidos de enseñanza para orientar el trabajo con los niños y niñas en el preescolar, se manifestó que los primeros trazos realizados a través de las actividades de dibujo tendrían un gran efecto en el proceso posterior de aprendizaje, en especial en la adquisición de la lecto-escritura y en el desarrollo de la creatividad.

En el proceso de la expresión infantil en las artes plásticas, según el MEN (República de Colombia, Ministerio de Educación Nacional - MEN, 1987), la maestra debía considerar que el niño o niña atravesaba una serie de etapas que comenzaban con el Garabateo, que a su vez incluían una serie de fases entre las que se encontraban la del garabateo sin finalidad o desordenado, en la que realizaban representaciones empleando líneas gruesas o finas con longitudes y direcciones distintas, sin control y sin el propósito de expresar algo definido. Al momento de pintar, el niño o niña podía manchar «áreas de la superficie buscando satisfacer una necesidad de movimiento sin mayor control sobre su actividad motriz» (p. 87).

El garabateo se convirtió en una expresión preliminar del niño o niña sobre lo circundante, sobre aquello que percibía en el ambiente en el que vivía, a través del cual no solo se permitió la manifestación de sus emociones o la adquisición de los conceptos propios de la pintura y el dibujo, sino que mediante la incursión de los niños y niñas en esta actividad se facilitaría la conducción de la palabra escrita, aspectos estos fundamentales para su desarrollo.

Superada esta etapa del garabateo desordenado, vivenciarían y se introducirían en la etapa del garabateo orientado, con una finalidad específica y controlado, en el que realizaban «temas con base en la repetición de líneas circulares o longitudinales» (p. 87), a través de lo cual lograban una mayor seguridad y confianza en sí mismos y en sus trabajos, estableciendo una relación directa entre sus movimientos y las líneas que utilizaban para expresar en el papel aquello que percibían de su mundo circundante; pero además de ello, con el tiempo y la apropiación de ciertas técnicas y habilidades con la pintura y el dibujo, podrían acercarse al dibujo de líneas más complejas pero factibles de realizar con el empleo de todo el brazo.

En conjunto con lo anterior, el saber escolar estético se orientó al desarrollo de la creatividad y de la sensibilidad mediante la vivencia por parte de los preescolares de experiencias artísticas relacionadas con la plástica — pintura, escultura, modelado-, con mayor concentración en aquellas actividades que incluyeran habilidades como la coordinación motriz fina. Fue por esa razón que se diseñaron actividades de plegado, rasgado, manejo de hilos y agujas, dáctilo-pintura, collage y elaboración de títeres, a través de las cuales se enfrentó a los niños y niñas al manejo de diferentes elementos que contribuirían al desarrollo de muchas más habilidades que posteriormente les servirían para asumir los retos de los grados superiores. 
Conforme a esto, se sugirió a las maestras durante esta etapa de iniciación al dibujo que no cuestionasen a los niños y niñas respecto a sus intenciones expresivas o lo que comentaran sobre aquello que intentaban dibujar, pues las manifestaciones sobre el papel no tenían un propósito representativo; por tanto, tampoco era pertinente plantearles algún tema en particular para dibujar. Frente al modelo, se dijo que los niños y niñas comenzaban «(...) a romper el material y se inicia la formación de rollos que corresponden en dibujo al garabateo longitudinal y en la formación de pelotas, que corresponden en dibujo al garabateo circular» (República de Colombia, — MEN, 1987, p. 88). Avanzada esta etapa el niño o niña incursionaba en la fase del pensamiento imaginativo o del garabateo nominado, en la que comenzaba a otorgarle un nombre a las representaciones dibujadas.

Al culminar esta fase, los niños y niñas ingresaban a la etapa pre-esquemática, en la que los garabatos comienzan a desaparecer para dar lugar al dibujo de objetos afines a su realidad, representando, entre otras cosas, figuras con forma humana, dibujando sin proporción y empleando indiscriminadamente los colores. Con posterioridad a esta etapa, enfrentan una nueva fase de la autoexpresión: la esquemática, a través de la cual trabajan sus propios esquemas y conceptos individualmente, expresando figuras humanas con mayores detalles, mezclando colores de manera correspondiente con la realidad y diferenciando los espacios en el dibujo realizado. la fase final de la autoexpresión plástica es la de socialización, en la que el niño o niña, a través de sus representaciones artísticas, establece conciencia de pertenecer a una colectividad y de las relaciones entre la escuela y la familia; las figuras humanas se diferencian en el sexo, y aparecen muchos más detalles que acercan más sus dibujos a lo observado en la realidad.

Entre los contenidos que se abordaron para la enseñanza del dibujo estaban el aprendizaje fundamentado en la teoría del color, temática con la que se buscaba acercar a los niños y niñas al conocimiento de la naturaleza de los colores, a su identificación y manejo como fundamento «para el desarrollo de todas las posibilidades de expresión de esta área» (República de Colombia, - MEN, 1987, p. 93). Junto con este contenido se introdujo la enseñanza del Círculo Cromático pues se consideró que a través de esta temática se aproximaban a la clasificación de los colores, a sus cualidades, y por supuesto, al estudio de los mismos, reconociendo en esos análisis los conceptos de brillantez, pigmentación, transparencia, mezcla, matización, densidad, tonalidad, temperatura y valor de los colores, agrupándolos además, según su composición y propiedades, dando lugar a la caracterización y reconocimiento de los colores primarios, de los colores secundarios y de los intermedios propios del círculo cromático; asociado a ello se enseñaron los colores complementarios y los colores análogos.

\section{La literatura infantil}

Otro de los contenidos abordado junto con el dibujo fue la literatura infantil que se relacionó, de una parte, como la escritura para los niños y niñas, y de otra, la escrita por los niños y niñas. En relación con los textos escritos para los niños y niñas se encontraban los cuentos mediante los cuales se favorecían los procesos para que adquiriesen los conocimientos necesarios y generales de la vida a través de los elementos de orden mágico o fantástico, pues se comprendía entonces, que la realidad tenía «en la fantasía su mejor vía de entrada en la mente infantil» (República de Colombia, —MEN, 1987, p. 96).

\section{Las dramatizaciones}

Como complemento de lo anterior, se introdujo en el aula la dramatización como una posibilidad de exploración de las capacidades de creación de los niños y niñas, de expresión de sus emociones y de las representaciones de la realidad inmediata, para lo cual las maestras podían recurrir, entre otras cosas, al empleo de diversos materiales como por ejemplo los títeres, que es un recurso educativo de ayuda visual y un impulsor de ideas que permite la adquisición de conceptos, valores, actitudes, 
comportamientos, y que puede ser acogido y valorado por los niños y niñas de preescolar para lograr los propósitos de aprendizaje establecidos.

Dicho recurso se utilizó para implementar en el aula el teatro de títeres, «un elemento integrador de gran valor pedagógico» (República de Colombia, - MEN, 1987, p. 105), en la medida en que vinculaba asuntos literarios, de las artes plásticas, la música y las manualidades; es más, el teatro de títeres favorecía que los niños y niñas trabajaran en grupo e idearan las acciones para el montaje, la realización de obras de teatro y la producción de los parlamentos y guiones que dirigían la puesta en escena, que a su vez podrían relacionarse con temáticas que involucraran nociones básicas de pre-lectura, de pre-matemáticas, de los cuidados ante enfermedades contagiosas, del cuidado de la naturaleza, del aprovechamiento del sol en las regiones frías o de la utilidad de la escuela, entre otras temáticas.

\section{La educación musical}

La educación musical se involucró en el nivel preescolar como un contenido de enseñanza propio de la educación estética, y se justificó por ser «una de las mejores formas de expresión y comunicación que tiene el niño» (República de Colombia, Ministerio de Educación Nacional-MEN, 1987, p. 116), mediante la cual se consideró factible el desarrollo de la sensibilidad auditiva, de la coordinación psicomotriz, del movimiento y la estimulación de los centros de aprendizaje, ya que el niño «al tener que reproducir ritmos y melodías, ejercita su memoria» (p. 116).

\section{Reflexiones finales}

La exploración histórica sobre la procedencia, función y funcionamiento de los saberes escolares estéticos en el preescolar público bogotano en la década de los 80 , permitió no solo dar cuenta de una racionalidad educativa que instalaba unas formas particulares de comprender la escuela preescolar, al maestro o maestra, el conocimiento y, por supuesto, la educación, que como efecto de una multiplicidad de prácticas se transfiguró posteriormente para posibilitar la irrupción de unas condiciones educativas de existencia distintas.

En el marco de esta racionalidad en la que se impulsó la inclusión de los procesos tecnológicos en la educación, que apostó por la renovación curricular de un sistema educativo colombiano en crisis que implementaba la tecnología educativa como acción de intervención en la enseñanza y en los procesos de planificación curricular, se introdujo en el preescolar la idea del desarrollo infantil como proceso asociado a la enseñanza de contenidos escolares acoplados a las áreas del conocimiento, lo que significó la incorporación de materias escolares como la educación estética, a través de la cual se legitimó una manera particular de enseñar, y se reguló la formación de unos niños y niñas creativos, sensibles, que apreciaran lo bello y lo bueno, que se expresaran con la música, el dibujo y las dramatizaciones - condiciones acordes con las necesidades escolares y los requerimientos sociales del momento-, pero con el que también se les preescolarizó y aprestó para enfrentar los retos de la escuela primaria.

Muchos de estos contenidos de enseñanza estéticos se han ido reconfigurando, deslegitimando, perdiendo su condición de verdad, desvirtuándose, transformándose o diluyéndose en el tiempo para permitir la instalación de otras formas de enseñanza acordes con la racionalidad imperante, que trascienden esa concepción de educación estética de los años 80.

En suma, rastrear los saberes escolares estéticos en el preescolar de la década de los 80, permitió evidenciar el sentido que se le atribuyó entonces a este nivel educativo, pero también visibilizar el estatus que tuvo este saber escolar durante este periodo frente a otros saberes, mostrando sus transfiguraciones, variaciones, permanencias, desvanecimientos y aquello en lo que se ha ido convirtiendo en el presente, con lo que se desnaturaliza su existencia y se valida su condición fluctuante en el tiempo, conforme a la racionalidad de cada momento de la historia, lo que da apertura a otros 
estudios interesados en la exploración de los saberes escolares estéticos — procedencia, función, funcionamiento - en la escuela pública en general y en el preescolar en particular.

\section{Lista de referencias}

Álvarez, A. (2008). Historia de los saberes escolares de las relaciones entre disciplinas cientificas y saberes escolares. IV Congreso Colombiano de Historia. Tunja 12-16 de agosto, mesa 48, Boyacá, Colombia.

Boada, L. (2015, 10 de octubre). Entrevista realizada por Cárdenas-Forero. Bogotá, D. C.: Texto impreso.

Cárdenas-Forero, Ó. L. (2015a). La participación de docentes de preescolar público en el Movimiento Pedagógico Colombiano. Revista Latinoamericana de Ciencias Sociales, Niñez y Juventud, 13(2), 657-669. doi:10.11600/1692715x.1327091714

Cárdenas-Forero, Ó. L. (2015b). Historia de los saberes escolares en el preescolar público bogotano. Revista Infancias Imágenes, 1(15), 89-101. doi:10.14483/udistrital.jour.infimg.2016.1.a06 Recuperado de: http://revistas.udistrital.edu.co/ojs/index.php/infancias

Cárdenas-Forero, Ó. L. (2016). Genealogía de la maestra de preescolar en la escuela distrital de Bogotá (1980-1990). Revista Educación y Ciudad, 30, 41-51.

Cárdenas, M., \& Boada, M. (2002). El Movimiento Pedagógico (1982-1998). Idep. Historia de la Educación en Bogotá, II, 195-225.

Castellanos, M. (2014, 5 de marzo). Entrevista. Bogotá, D. C.: Texto impreso.

Chervel, A. (1991). Historia de las disciplinas escolares. Reflexiones sobre un campo de investigación. Revista de Educación, 295, 59-11. Recuperado de: http://www.mecd.gob.es/dctm/revista-deeducacion/numeroscompletos/re295.pdf?documentId=0901e72b8130f412

Goodson, I. (1991). La construcción social del curriculum. Posibilidades y ámbitos de investigación de la historia del curriculum. Revista de Educación, 295, 7-37. Recuperado de: http://www.mecd.gob. es/dctm/revista-de-educacion/numeros completos/re295.pdf?documentId=0901e72b8130f412

León, T. (2015, 26 de junio). Entrevista realizada por Cárdenas-Forero. Bogotá, D. C.: Texto impreso. Marín, D. L. (2015). Una cartografía de los saberes escolares. En C. Aranguren, D. Rubio, D. Marín, F. González, H. Riveros, H. Rodríguez, ..., V. González (Eds.), Saberes, Escuela y Ciudad. Una mirada a los proyectos de maestros y maestras del Distrito Capital, (pp. 13-38). Bogotá, D. C.: Instituto para la Investigación Educativa y el Desarrollo Pedagógico (Idep).

Martínez-Boom, A. (2004). De la escuela expansiva a la escuela competitiva. Dos modos de modernización en América Latina. Barcelona: Anthropos.

Martínez, A., Noguera, C., \& Castro, O. (1994). Currículo y modernización. Cuatro décadas de educación en Colombia. Bogotá, D. C.: Foro Nacional por Colombia, Corporación Tercer Milenio.

Martínez, M. I. (1983). Características de la educación pre-escolar de las escuelas oficiales del sector nacional y distrital que funcionan en Bogotá, Distrito Especial. (Trabajo de Grado). Universidad Externado de Colombia, Bogotá, Colombia.

Morales, E. (2015, 12 de febrero). Entrevista realizada por Cárdenas-Forero. Bogotá, D. C.: Texto impreso.

República de Colombia, Ministerio de Educación Nacional-MEN. (1978). Decreto 1419. Bogotá, D. C.: República de Colombia, Ministerio de Educación Nacional-MEN.

República de Colombia, Ministerio de Educación Nacional-MEN. (1984). Decreto 1002. Por el cual se establece el plan de estudios para la educación preescolar, básica (primaria y secundaria) y media vocacional de la educación formal colombiana. Bogotá, D. C.: República de Colombia, Ministerio de Educación Nacional-MEN.

República de Colombia, Ministerio de Educación Nacional-MEN. (1987). Currículo de Preescolar. 
Desarrollo del niño y algunos temas relacionados con el preescolar. Bogotá, D. C.: Case.

Vasco, C. E. (2011). La presencia de Piaget en la educación colombiana (1960-2010). Colombiana de Educación, (60), 15-40. Recuperado de: http://revistas.pedagogica.edu.co/index.php/RCE/ article/view/836/845 